\title{
Recoverable Catalysts non-covalently bound to a hyperbranched polyelectrolyte
}

\author{
Ernst Schwab, Stefan Mecking
}

\section{Supporting Information}

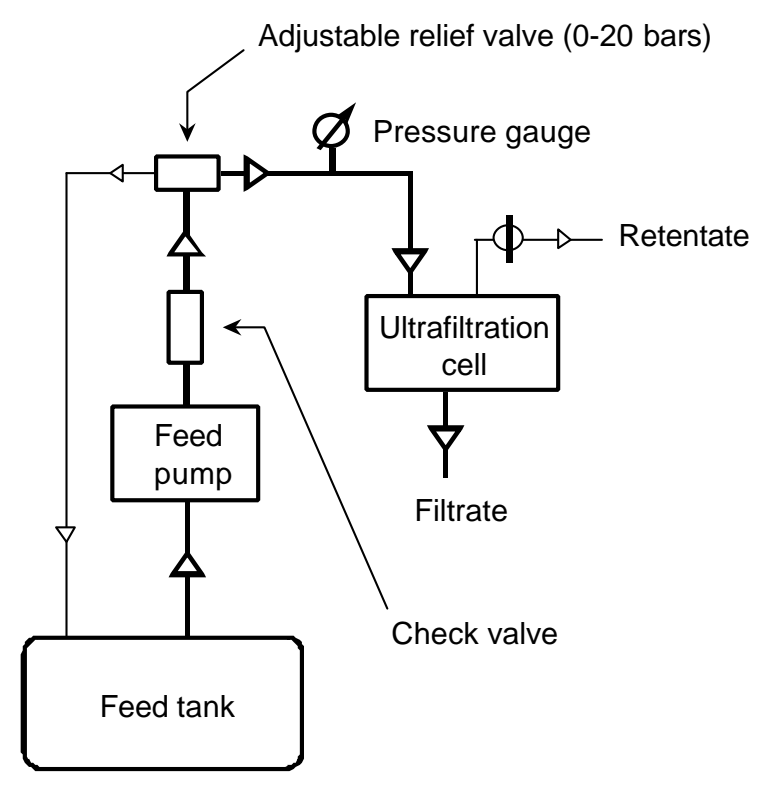

(a)

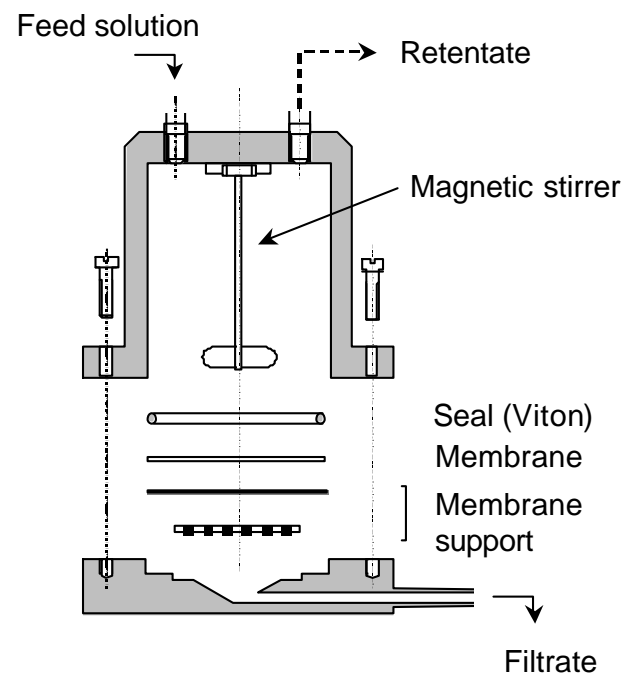

(b)

Figure S1. Flow diagram of the ultrafiltration apparatus (a) and cross section of the ultrafiltration cell (b). 